\title{
Performing Place: Tourism and Touring with the Leweton Cultural Village
}

\section{Thomas Dick}

\section{(2) OpenEdition Journals}

Electronic version

URL: http://journals.openedition.org/jso/7465

DOI: $10.4000 /$ jso.7465

ISSN: $1760-7256$

\section{Publisher}

Société des océanistes

\section{Printed version}

Date of publication: 31 December 2016

Number of pages: $55-55$

ISSN: 0300-953x

\section{Electronic reference}

Thomas Dick, "Performing Place: Tourism and Touring with the Leweton Cultural Village », Journal de la Société des Océanistes [Online], 142-143 | 2016, Online since 31 December 2018, connection on 04 May 2019. URL : http://journals.openedition.org/jso/7465 ; DOI : 10.4000/jso.7465 


\title{
Permorming Place: Tourism and Touring with the Leweton Cultural Village
}

by

\author{
Thomas DICK*
}

\begin{abstract}
Embodying dual legacies (ancestral and colonial), communities throughout the Pacific Islands are configuring and re-configuring themselves, their cultures and, consequently, the world around them. This article examines the performative articulation of cultural heritage in Northern Vanuatu. Taking the case of the Leweton "cultural village" - performers of the Vanuatu Women's Water Music - this article explores the deliberative creation of diasporic identities. The process is complexified by the intangible and mobile elements of the water music as Leweton is a destination for tourists visiting the islands of Vanuatu, as well as an ensemble often "on tour" performing at international festivals and events.
\end{abstract}

KeYwords: Vanuatu, water music, articulation, chorography, Mwerlap, diaspora, knowledge

In September 2015, a conference held in Fiji titled Scripting the Development Narrative Through Indicators and Dance brought together a range of people to explore alternative approaches to development in Melanesia (see Cullwick, 2015). There is a real flourish to this title - a jouissance - intensified by an academic over-exposure to less-transgressively-titled research conferences. There is something of an intergrading chiasmus in the effortless transition from the literal to the corporeal, from mimesis to kinesis "scripting... narrative... dance" that lends a poetic quality to the quantitative neo-liberal "development... indicators". One can imagine an undergraduate

\section{RÉSUMÉ}

Les habitants du Pacifique reconfigurent sans cesse leurs communautés, leurs cultures et par conséquent le monde qui les entoure. Cet article examine le cas du "village culturel" de Leweton - interprètes de Vanuatu Women's Water Music (" La musique d'eau des femmes du Vanuatu ") - l'articulation performative de leur patrimoine culturel et une création délibérée des identités diasporiques. Le processus est rendu plus complexe par les éléments immatériels et mobiles de cette musique d'eau, étant donné que Leweton est à la fois une destination pour les touristes visitant les îles du Vanuatu ainsi qu'une troupe souvent "en tournée ", se produisant lors de festivals et d'événements internationaux.

MotS-CLÉS: Vanuatu, water music, articulation, chorography, Mwerlap, diaspora, knowledge

program in a liberal arts faculty called Scripting (or Choreographing?) the Development Narrative Through Dance. It is somewhat harder to imagine an economics program called Dancing Development Indicators. ${ }^{1}$

This knowing misapprehension is reminiscent of the (misapprehended) idea of the "developman" epoch (Sahlins, 1993: 17). Sahlins (1993: 17) proposes this term as an episodic label that captures "an indigenous way of coping with capitalism". Two decades later, in a recent issue of this journal, Leach (2014) presents an indigenous narrative that describes our current epoch as the "time of money" in specific relation

1. Though there is an international competition called "Dance Your Thesis" http://gonzolabs.org/dance/.

"Wantok Musik, Further Arts, and The Planet Spins, tommyd@theplanetspins.com 
to the way Reite people in Papua New Guinea are changing their approach to, and understanding of, the value of land. Both authors, with their nuanced reflexivity, were trying to influence at the most fundamental level, the way that we "know" the idea of knowledge itself. Both privilege Melanesian voices articulating complex and ambiguous perspectives. In doing so, they gently - almost surreptitiously - create space in academia for different modes of knowing and different ways of understanding terms loaded with Western values, such as "development".

Inspired by the people of Papua New Guinea (who informed the work of Sahlins and Leach) and with reference to the conference title above, this article focuses on the dissonance of the "and" in the conjoining of "indicators" and "dance" as it embodies the transgressive implications of Pacific Island civil society that "knows" - and crucially - knows how to script a development narrative that values (measures, indicates) artistic and cultural performance, defines new conjunctions of the power of place, and nurtures the traces and promises of an enduring spatial nexus. The contemporary diasporic inflections of the Oceanian relationship to place reveal contingent openings for indigenous people to transform their world.

This article presents a way of understanding the dynamic trajectories and the pluralism of Oceanian actuality - islands/villages, urban towns, visiting and returning, assembling and reassembling. It extends Clifford's (2001) reading of Hall's articulation theory ${ }^{2}$ (in Grossberg, 1986; Hall, 1980) to demonstrate ni-Vanuatu strategies for cultural continuity and change in concert with global structures, such as the tourism industry. Decolonising societies and their post-national subjectivities "have their own roots and trajectories." (Clifford, 2001: 475)

\section{Approach and Method}

This article unfolds in dialogue with two perspectives on indigenous people's engagements with place. The first is James Clifford's (2001) keynote address for a symposium at the University of California, Santa Cruz, later published as an essay in The Contemporary Pacific. The second perspective is that of Michael Tawa (2002: 49) who explores an indigenous emplacedness - a "mode of being in a place, being placed, and being place" (italics in original). For Tawa this emplacedness is oriented by his personal experiences with the

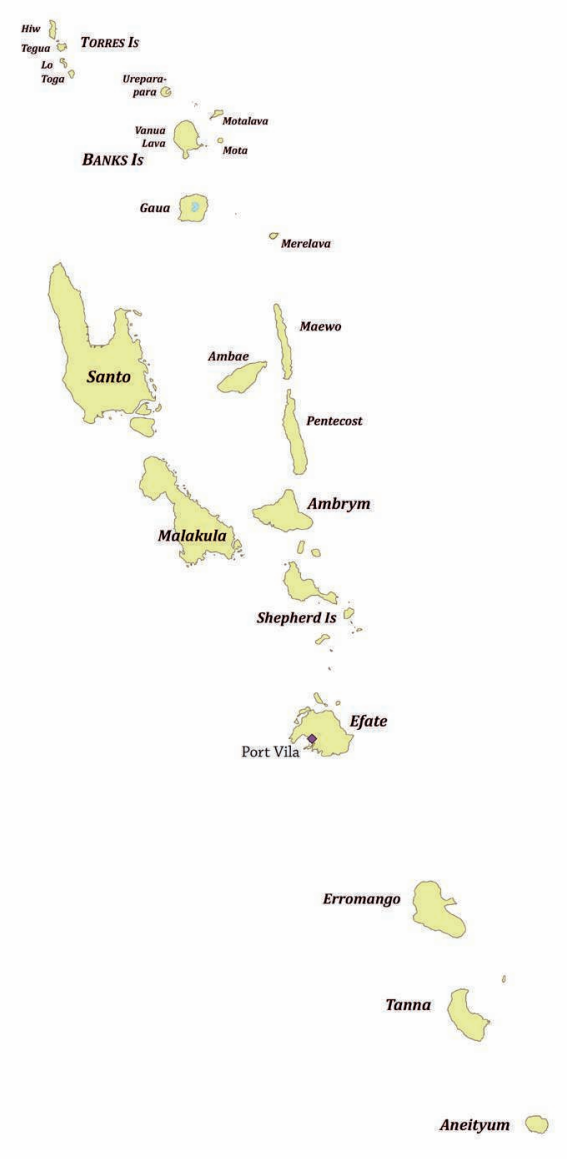

Map 1. - Map of Vanuatu (C) A. François, 2013, LACITO-CNRS)

Ngaanyaijarra communities around Patjarr and Warburton Ranges, Gibson Desert, Western Australia. I am not suggesting that place is understood in the same ways by Mwerlap and Ngaanyaijarra communities. Rather what the Clifford and Tawa analyses have in common is a critical reading of relevant theories: articulation and chorography (derived from the Greek khora for 'region'), respectively; that intersect with observations and conversations with Indigenous informants who themselves demonstrate an integrated embodiment of thought-in-action, mind-body, and theory-practice in their engagement with place.

This paper is the fourth in a series of articles that draw on long-term, multi-sited, coactivity and co-performance (Conquergood and Johnson, 2013: 93) via participant engagement with artists and producers from Vanuatu. In this article I present data and analysis regarding a

2. For readers unfamiliar with Stuart Hall's "articulation theory", the term is differentiated from the common usage of putting thoughts or feelings into words, or vocalising clearly those words. Instead it refers to the less common meaning of a specific joint, or a state of being jointed - like an articulated truck (a semi-trailer) or the articulated joints in the human jaw, or legs. 


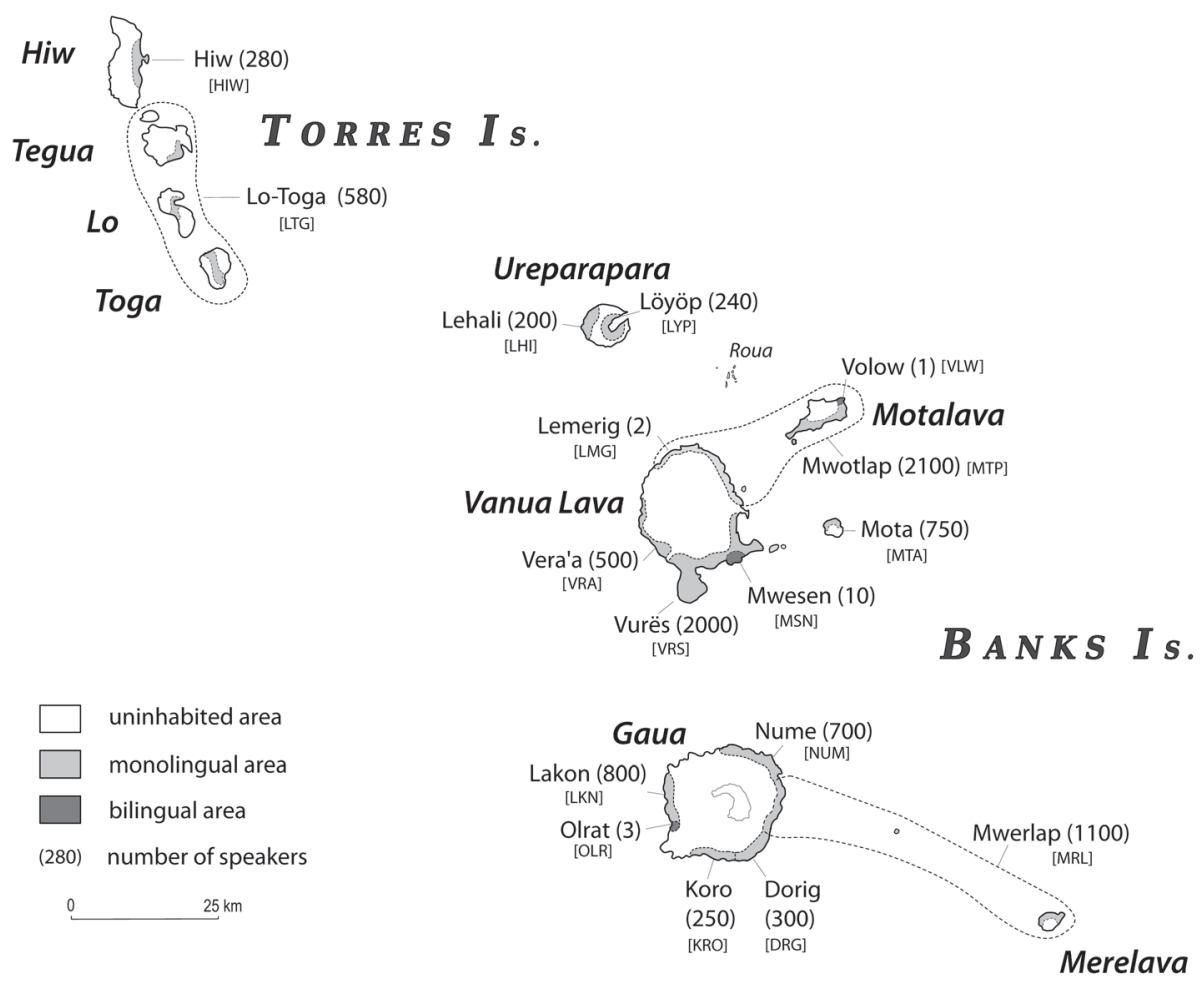

MAP 2. Map of Banks and Torres Islands (@ A. François, 2013, LACiTO-CNRs)

sub-national Melanesian diaspora in the north of Vanuatu - the Mwerlap-speaking community. The Mwerlap-speakers originate from the islands of Merelava and Gaua (see Map 1). I have documented elsewhere (Dick, 2014b) the agency of the community and the colonial and postcolonial shifts in migration patterns that have led to the formation of the Leweton "village" - a settlement/community in a peri-urban area outside of Luganville, on Espiritu Santo, an island in the north of Vanuatu in Sanma Province. Luganville itself was first established during World War II when the Americans, seeking a secure base for staging action in Pacific, selected the site as a military base. Thus, the people in Luganville are either recent immigrants or the direct descendants of people who have migrated from other parts of Vanuatu, or from overseas. The members of the Leweton group are part of the Mwerlap-speaking sub-national diaspora from the islands of Merelava and Gaua, and many members of the community speak some of the languages of Gaua, such as Nume and Lakon (see Map 2). In this sense, urban Vanuatu in general, and Luganville in particular, can be understood as a site of complex intercultural and transcultural engagement, a contested zone, and a cultural transition area (Bhabha, 2012; Pratt, 1991; Turner et al., 2003).
This article is also intended to be read in conjunction with a DVD "Vanuatu Women's Water Music" (henceforth "vwwwm") and an essay in the liner notes of the DVD titled "The History of the Leweton Cultural Village" (Leweton Cultural Group, 2014; Wessergo et al., 2014). The Leweton community is developing some renown for its performances of the ëtëtung (the Mwerlap word for "water music") and stringband matto (a term that combines a word from Bislama, stringband, and a word from Mwerlap, matto, which are used together to refer to the form of Melanesian string band music blended with traditional percussion from the Banks Islands). I have had the great privilege to live in Vanuatu for almost a decade between the years of 2000 and 2009 . For the last three years I was based principally in Luganville, the second largest town in Vanuatu. While I relocated to Australia in 2009, I have maintained regular contact with friends and family in Vanuatu. In 2011 (twice), 2013 (twice), 2014, and 2015 I coordinated tours of Australia, and/or Malaysia, and/or New Zealand for members of the Leweton group.

While the members of the Leweton community are rarely interested in articles published in academic journals, they are engaged in their own research and producing their own knowledge, 
such as the vwrwm and "The History of the Leweton Cultural Village" that describes the way the women of the Mwerlap families came together for the contemporary crafting of the water music. They are interested in the film and the way it creates opportunities for touring and for them to share their own thoughts on the processes involved in the research/filming, even at academic conferences. Thus there is a complex, reflexive tension that is a function of the different configurations of research, embodied on the one hand in myself as the researcher and on the other hand members of the community some of whom are now conceiving and driving their own research agendas. There is an important shuttling of implications - backwards and forwards between the data and the modes of knowledge.

From my perspective, the reflexive tension is mitigated by my embedded-ness in the project and the way that a potentially conflicted positionality becomes a methodological strength. For example, despite the fact that I am often accused of, in Bislama, "fulumap hed blong man" (filling up people's heads), or "go long we tumas nao" (going too far) with plans or ideas, I am not perceived as an observer. Rather, I am treated as an adopted family member with a set of perceived propensities that various community members are able to leverage. I embody a set of obligations that impact the research without being methodologically significant. This creates the conditions for an integrated analysis of contemporary indigenous engagements with place, such as are explored in this article, along with multiscalar and multilateral strategies of articulation and de-articulation. The VWWWM DVD, the tours and the performances form part of the data. And simultaneously they are in and of themselves research outcomes - modes of presenting knowledge that belongs to people in a specific place.

Anthropologists working in Vanuatu (and throughout Oceania) have detailed the permeability of personhood, place and language (for example, Bonnemaison, 1994; Tryon, 1996; Hess, 2009; Durand, 2013; Taylor, 2008; Jolly, 1994; Bolton, 2003; Mondragon, 2009; Patterson, 2002). In this paper, I build on many of these ideas, bringing new insights into the processes of displacement and emplacement of niVanuatu people who are using the performance of their cultural heritage as a vehicle for (re) locating themselves on multiple scales. I argue that the way the Mwerlap diaspora is engaging performatively in a political process of "taking place of place" (Tawa, 2002: 54). Specifically I will demonstrate that even though the members of the Leweton group reside away from Merelava, their diasporic imaginings are shaped by processes and relationships deeply anchored to the locative identity of their "foundation-place" (Bonnemaison, 1994: 234); see also Durand,
2013: 69-78), Hess, 2009: 42-66).

A departure from Clifford is that I am principally exploring the way the Mwerlap people articulate sites of their own indigeneity as opposed to articulating with broader indigenous movements, as such. Data is presented that foregrounds people's strategies of articulation and demonstrates a performative revisioning of space that opens up transformational contingencies for diasporic communities. This data includes insights and reflections drawn from quotidian coactivity with the community. It is further augmented with autoethnographic vignettes: "in which people undertake to describe themselves in ways that engage with representations others have made of them" (Pratt, 1991: 35). The first section provides some contextual markers for the paper, including some reflections on the beginnings of my relationship with the Mwerlap people. It also describes the ways that the chorographic and coactive approach have resulted in a range of textual outputs that are part of the context, part of the data, and new knowledge in their own right. The main body of the paper unbraids the three sites or conjunctures of Mwerlap articulation on: the local level, the national level, and the international level. In many instances I have integrated discussion and analysis into the presentation of data to which it directly relates. While this may be jarring for the reader, the dissolution of observer and observed in the project, that is, my embedded-ness in the data, creates an opportunity for a deeply integrative analysis of contemporary indigenous engagements with place and multilateral strategies of articulation and de-articulation. A more traditional discussion section follows, leading to an analysis of the impacts of this study in terms of coproducing new knowledge and unfamiliar (that is, non-Euro/Western) modes of knowledge. Articulating the findings of this project with those of a recent study of the socio-linguistic ecology of the region (François, 2011, 2012) suggests a continuity of processes of linguistic innovation that aligns with modes of configuring social, cultural and political interconnectedness and differentiation: the strategies that the Mwerlap/ Leweton community deploys and has deployed in relation to pre-colonial situations are useful, contingent, relational, temporal tactics in the contemporary politics of spatial articulation though they are being applied on different scales for different reasons.

\section{Beginnings, Chorography and Coactivity}

The Leweton Cultural Village is best known for their performances of the "women's water music" (see Figure 1.) whereby a group of approximately 


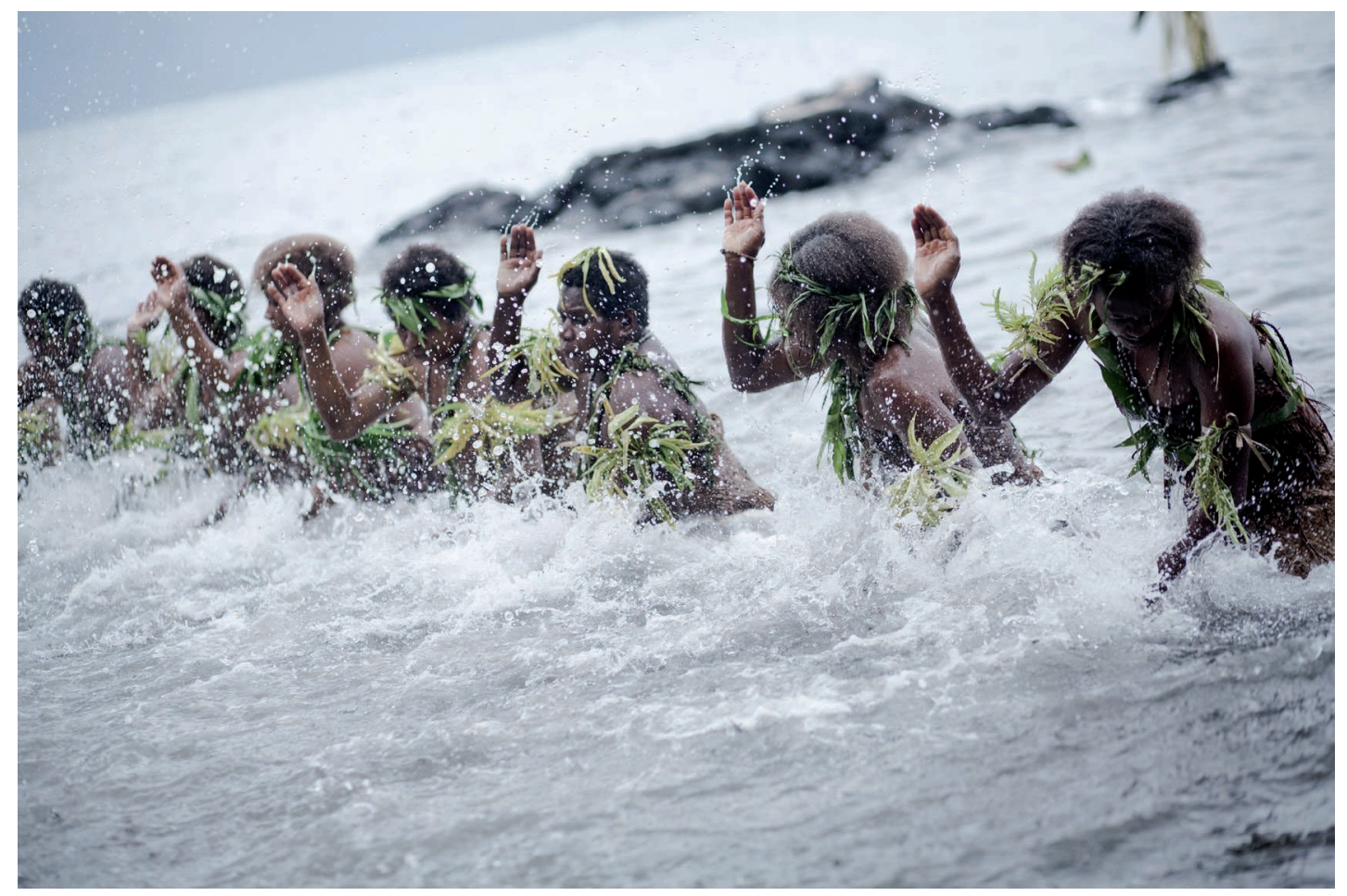

Figure 1. Women's Water Music (C) Cristina Panicali, 2013, Vanuatu

six to ten women stand thigh-deep in still water and splash, scoop and otherwise disturb it to create a range of beats and rhythms (Dick, 2014b; François and Stern, 2013: 100-101). My first encounter with the women who perform the water music was in 2007, in Luganville, just before the Leweton village was officially established. Over the next few years I worked together with the village. We implemented a plan to produce a professional recording of the water music and generate touring opportunities for the group to perform at international festivals. Between 2009 and 2011, a delegation of Vanuatu music industry representatives attended the European World Music Expo "womex". The Vanuatu delegation presented amateur video productions of various Vanuatu musicians to a range of promoters, bookers, and festival organizers. In 2010, a proposal was accepted for the Leweton group to perform the water music in the 2011 edition of the Rainforest World Music Festival (RWFM) in Sarawak, Malaysia. Despite this successful outcome, the Vanuatu delegates reported that many producers and promoters at wOMEx failed to recognise the music and dance of Vanuatu as relevant to the world music industry. Instead, some suggested that music performed in the islands of Vanuatu, in its local setting, does not fit into the rubric of world music and perhaps was better suited to presentation at a tourism trade fair. It is beyond the scope of this article to analyse and critique the world music industry, rather this anecdote acts as an affective benchmark of the types of narratives and perspectives prevalent in the creative and cultural industries that marginalise indigenous performers (for a comprehensive discussion of these issues see Feld, 2000). This anecdote also exemplifies the investment that the Leweton group has made in producing real impacts in terms of what Grossberg (1992: 56) acknowledges as the "constructing, dismantling, and reconstructing of structures".

During the course of the planning, the touring and the follow-up discussions after the trip to Malaysia, members of the community expressed a desire to present the results of their own research - a story in a form accessible to a broad audience that included their own community, other ni-Vanuatu communities, tourists who visit their village to see the water music and also the international audiences at festivals in other countries. To facilitate a sense of mutual understanding of the intersections of my research project and the Leweton research project, I used the endogenous kinaesthetic framework of sand drawings. Sand drawings are a kind of "dance" of the vibrant materiality of Melanesian ontology. A person tells a story and figuratively presents that story using material from the liminal space between the land and the sea as palette, paint and performance space. In Vanuatu, the designs work, in tandem with stories, on multiple levels and scales. The drawings are both a dynamic embodiment and kinetic abstraction of: kinship systems, 


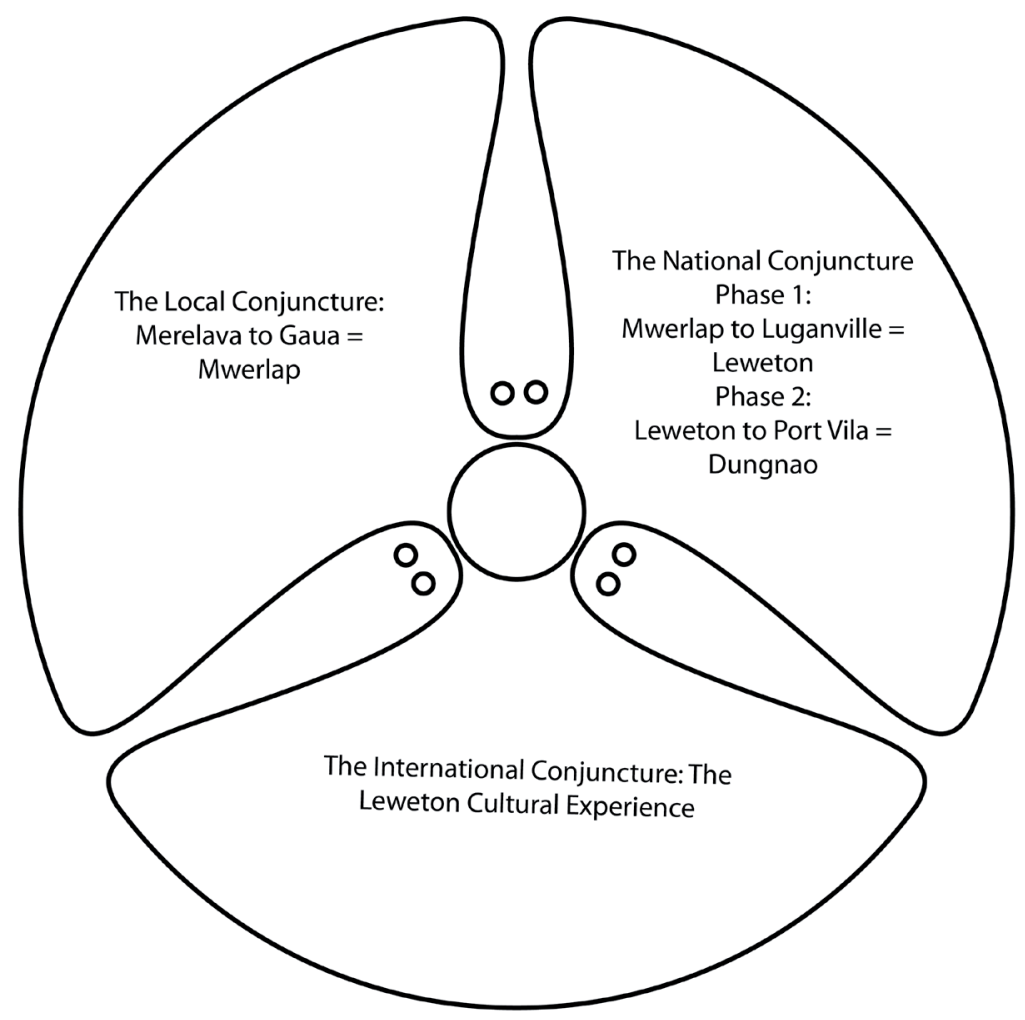

FIGURE 2. - Sand drawing of three flying foxes eating a breadfruit with audience/ conjuncture mapping (C) B. Foley and T. Dick, 2015, Brisbane)

navigation and orientation techniques, ancient and modern histories, horticultural knowledge, and current events. Using the sand drawing of three flying foxes eating a breadfruit, I mapped the three audiences (local, national/domestic, international) onto the drawing as a way of expressing the multiscalar nature of the audience engagement with the Leweton Cultural Village (see Figure 2) ${ }^{3}$. The local scale corresponds with the Mwerlap community in Merelava and Gaua, and the narrative development of the Leweton water music innovations; the national scale corresponds with the formation of the Village, the operation of a tourist attraction and an iconic cultural performance; and the international scale corresponds with the export of a world music product for the arts/music festivals touring circuit. This diagram was especially useful as a tool for presenting my research project to community members in a way that was accessible and engaging.

One of the first stories that the community shared is the narrative of the development of the water music: ëtëtung. The story, dating back to 1974 (Wessergo et al., 2014) is presented in the Vwww DVD as "The History of the Leweton Cultural Village". It was originally presented to me as a written statement by one of the men, the husband of Hilda Rosal Wavales, the woman recognised as the custodian of the ëtëtung. Recognising that the women were integral to the re-configuring of the water "games" as a contemporary musical genre, in this article I revise the narrative as "The Herstory of the Leweton Cultural Village" (henceforth "Herstory"). The Herstory was translated from Bislama to English and revised to fit the requirements of the liner notes for a commercial release on a world music label specialising in the music of Melanesia, Wantok Musik. While the original Bislama version of the Herstory is a distinctly autoethnographic text, in the sense defined by Pratt (1991: 35), the somewhat lyricised English version presented with the DVD still retains enough of the character and the intent of the original to warrant this label. It is a critical or historical genealogy of the innovations on the water music and a claim to the intellectual property rights emanating from the creation of the ëtëtung (Dick, 2014b, 2015a). Just as European history/herstory is contested, there may be community politics, controversies and uncertainties in the background of the narrative presented to me. Whatever controversies exist, the Herstory provides an engaging contextualisation for the vwww film and it describes a trajectory of innovations related to the water music.

The vwww film has a slightly more complex pedigree. The culmination of almost four years of collaborative work between myself and the Leweton community, the film was partly financed by Further Arts - a Vanuatu-based not-for-profit

3. For a description of how this sand drawing relates to the research and an analysis of its chorographic value see Dick (2015a). 
organisation creating employment pathways and opportunities for young artists and producers in the arts and cultural sector - and the Wantok Musik Foundation (Wantok Musik) a highlyregarded, Australian not-for-profit label in the international world music industry, known for producing Melanesian and Indigenous Australian music. ${ }^{4}$ Releasing the film on a record label was a strategic choice for the Leweton group. For the Leweton group, release on the Wantok Musik label was a tactical response to the perspective of the womex delegates, described above, and the expectation was that distribution through Wantok Musik would project a particular status of artistic authority and quality to the international industry. Wantok Musik engaged an Australian sound artist, Tim Cole, to direct and record the film. Cole worked with the Leweton community, and several young people engaged by Further Arts and other local partners to record the footage and the audio over a two-week period in November 2012. With this complex arrangement in mind, both the Herstory, the vwwM film, and the various tours can be understood to be the result of coactivity - a form of dialogic performance that embraces and complicates diversity, difference, and pluralism (Conquergood and Johnson, 2013: 93). Madison (2005) describes it as living in "embodied engagement of radical empiricism, to honor the aural/oral sounds that incorporate rather than gaze over" (p. 168, emphasis in original).

In his review of the cultural-environmental context of the Mwerlap water music Hayward (2015) argues that there is a "localized creative dialogue with the specificity of place" (117) that characterises the Leweton group's performances. $\mathrm{He}$ recognises this as convergent with Feld's idea of acoustemeology (2012: xxvii). Working with the Kaluli people in the Southern Highlands of Papua New Guinea, Feld, like Sahlins and Leach, was concerned with the limits of Western modes of knowing. Feld coined the term acoustemology "to join acoustics and epistemology, to argue for sound as a capacity to know and as a habit of knowing" (2012: xxvii). Following Hayward, these ideas dovetail with a chorographic engagement with place - an approach developed in an earlier publication of findings from this research project (Dick, 2015a; Olwig, 2008; Tawa, 2002).

In contradistinction to the use of the term archipelago, Hayward (2012a, 2012b) has introduced the term aquapelago, so as to privilege the marine-side of integrated dynamics involving human and non-human (inter)relations inbetween, throughout and with islands, their shores, seabeds and waters. These dynamics, what
Hayward calls "aquapelagic assemblages" (2012a), are performed entities that are premised on human presence. According to Maxwell (2012), aquapelagic assemblages imply "a radically interdisciplinary writing of the meanings of place" (23). Seas as places, he argues "are multiple and complex, known and unknown in their specificities... The concept of the aquapelago lays these knowings in front of us, inverting familiar figure-ground logics" (ibid.). Building on these ideas, I developed the nonrepresentational "diagram" in Figure 2. as an alternative way of conceptualising these knowings with an implied sensitivity to the indivisibility of society and nature, presentations of kinetic performativity in land/sea scapes that embody a spatially-anchored, maritorially-grounded indigenous longue durée (Dick, 2015a). As nonrepresentational theory tells us, "what pass for representations are apprehended as performative presentations, not reflections of some a priori order waiting to be unveiled, decoded, or revealed" (Anderson and Harrison, 2010: 19).

\section{Mwerlap Sites of Articulation: Local, National, International}

Applying these ideas to the Mwerlap water music, and the diasporic Leweton performances, Hayward states they are "generated by and regenerative of the specific aquapelagic context in which the community is embedded at particular historical moments" (2015: 118). The performances, the specific contexts in which they take place, and the particular audience (other villages, tourists, festival patrons, etc) can be understood, and in this section they are presented as, a braiding of three levels or conjunctures. These conjunctures reflect the (often arbitrary) "edges and borders [that] crosscut the region, defining conjunctures: local, national, and regional; urban, rural, and in-between; colonial, neocolonial, postcolonial" (Clifford, 2001: 471). Also, these conjunctures correlate with explicit commercial trajectories as well as more implicit political and pedagogical trajectories (and no doubt a range of others that are unknown to me). Importantly, the Leweton group recognise these conjunctures as contingent openings where tactics of (de-, re-) articulation for community benefit are oriented and operationalised by specific commercial and customary entities, as will be seen by the following description. Broadly, the local conjuncture corresponds with the Mwerlap community in Merelava and Gaua, and the narrative Herstory

4. I am involved with both of these organisations, on the Board of Further Arts, and as an independent producer/ researcher with the Wantok Musik Foundation. 
of the water music innovations; the national conjuncture corresponds with the formation of the Leweton village, the operation of a tourist attraction and an iconic cultural performance; and the international conjuncture corresponds with the export of a world music product for the arts/music festivals touring circuit.

As we begin to follow the fault lines of these conjunctures, Tawa's (2002) description of a (choreo- and) chorographic engagement with place is a reminder of the nonrepresentational significance of people and their locative identity in Oceania:

"Every place is a place where someone has come from, where something happened, where someone did something, where something was said or decided. More than that. Places are not contexts or containers for these events. Mythic events, stories and presentday encounters don't take place in country. Rather, they are the taking place of country as such-the performance of its own narration" (46).

\section{The Local Conjuncture: Merelava to Gaua = Mwerlap}

The local level of Mwerlap spatial articulation includes the island of Merelava and the east coast of Gaua (see Map 2.), which was colonized by Mwerlap speakers (Arutangai, 1987; Dick, 2014b; François, 2011, 2012). This level or site of articulation is the spatial nexus of the narrative of the water music innovations as documented in the Herstory. There are other groups of women, both Mwerlap-speakers and women from other language communities, performing water music, such as the Salap and Limoros groups. From the perspective of the Mwerlap-speaking people, Gaua can be understood as the frontier of a contested zone of cultural expression (language, arts, etc), and locative identity. Consider,

"the village of Jōlap (500 inhabitants) on the west coast of Gaua counts as many as three distinct languages, which are all heard in public every day: Lakon (itself a composite of two dialects Vurē and Qätärew), Olrat (and its variety Viar) and Dorig. These three languages have been spoken and transmitted by families in this village for more than three generations. To these one may add Koro, Mwerlap and Nume; these are the languages of immigrants (spouses, new settlers) and are spoken within certain households. There is enough multilingualism in the small population of this village for everybody to understand, and occasionally speak, each others' language(s)" (François, 2011: 183).

Intrigued by the fact that it is actually in Jōlap where the Herstory locates the genesis of the water music innovations, I enquired as to the conditions that led to this eventuality. To my mind it was somewhat odd that the genealogy of the water music was not spatially centred inside the Mwerlap territory, in the context of the importance of the genealogical function of the story, given that it asserts cultural and intellectual property rights over the innovations. In response to my enquiries, I was informed that of a story from some generations past, about a man from Merelava who married a woman from Jōlap and moved into the community in Jōlap. The people I spoke prefixed the story with the statement in Bislama that "Gaua hemi folem laen bl woman, be Merelava folem laen bl man" (Gaua is matrinlineal while Merelava is patrilineal). My interlocutors pointed to the fact that the implications of the story were self-evident in the interrelationships between: the WessergoWavales families, the Jollap and Mwerlap communities, and the genealogy of the water music innovations. As described in the Herstory these interrelationships are embodied in the marriage of the descendant of the man from the story above, Warren Wessergo, and Hilda Wavales. At first, this seemed to be something of a teleological argument to me, as Warren was both protagonist and narrator.

However, reviewing my fieldnotes, and rereading Tawa's description of the way indigenous disclosures of concealed implications often operate by way of deferral, the story started to make more sense to me:

\begin{abstract}
"Implications defer one to the other by way of an indefinite shuttling across juxtaposed and overlayed patterns. In a sense, this shuttling of implications does more than describe. It weaves the fabric of a place. It traces, presents and constructs place by mapping or registering the signs and tracks of intrinsic configurations and processes - traces left behind, and therefore past, but also carrying a forward promise, and therefore futural." (Tawa, 2002: 46, emphasis in original)
\end{abstract}

One wonders at what may be the implications for the Jōlap community in Tawa's visceral parsing of temporality. Indeed, the uncertainty of Jollap's future, while not a central concern of this article, does raise another important point about the dynamics of the contested zone - the edges and borders - in relation to the Mwerlap articulations/forces/ etc. Cultural edges, rather than being border zones between discrete social entities, are zones of social interaction, crossfertilization, and synergy wherein people not only exchange material goods but also learn from one another (Hau' ofa, 1993; Pratt, 1991). In the same way that ecological borders are places of biodiversity, so too 'cultural knowledge systems can intersect producing a richness of knowledge and practices that enhances the resilience of local societies' (Turner et al., 2003: 440). The fostering 
of differentiation, what François (2011) refers to as an "ideological emphasis placed on the value of local identities" (235) has been prevalent in Vanuatu society for thousands of years and there has been a constant state of flux between various communities. Functions, processes, and forces historically familiar to the Mwerlap local community are deployed in the articulation of Leweton (id)entities on the national and international levels.

\section{The National Conjuncture Phase 1: Mwerlap to Luganville $=$ Leweton}

The next level of articulated sites of the Mwerlap sub-national diaspora is the national level. At this level there are currently two sites, each site with its own entity. The first articulation was the establishment of the Leweton Cultural Village near Luganville, Espiritu Santo (described in Dick, 2014b). In summary, in 2008 a Mwerlap man named Sandy Sur was living on the fringe of Luganville, Espiritu Santo. Sandy, having worked for several years conducting tourists around northern Vanuatu on charter yachts, had first-hand experience with the demand for cultural products in the tourism industry. Sandy brought together the Mwerlap community living in and around Luganville and facilitated the establishment of a conscious community - a peri-urban "cultural village" - for the dual purpose of maintaining cultural heritage so that it may be presented to tourists in a commercial enterprise. They named their village "Leweton" being an acronym of the first few letters of the names of six of the villages they came from on Gaua and Merelava. With support from the New Zealand High Commission the Leweton group constructed a purpose-built pool for performing the water music and then constructed a "cultural village" around it.

This transformational moment is a critical juncture. It marks the point at which the dearticulated Mwerlap-speaking diaspora rearticulates itself as the Leweton Cultural Group. In the intercultural space of (peri-)urban Luganville the Mwerlap people from Merelava/ Gaua re-articulate a new entity - Leweton: a function of Mwerlap-ness spatially anchored in Luganville. From the perspective of the Mwerlap diaspora who were living in Santo, there is a transition from an in-between state - a liminal state of collective uncertainty where Mwerlapness was just one of many asymmetrically uncertain - virtual - cultural identities, jostling with other identities in Luganville. As Homi Bhabha writes, the spaces in between "provide the terrain for elaborating strategies of selfhood - singular or communal - that initiate new signs of identity, and innovative sites of collaboration, and contestation, in the act of defining the idea of society itself" (2012: 1). The transition, or perhaps transgression, from a liminal, inbetween Mwerlap indigeneity to a diasporic Leweton groundedness reconfigures, decentres, the entire Mwerlap identity. Lindstrom (2011: 2) has also traced the productive dialectic of diaspora highlighting the way "migrants model new urban settlements after island homes and also remake their village with urban experience and resources". In the story about the WessergoWavales family embodying the Merelava-Gaua (Jōlap) configuration (above), the deferral between the two sites creates a third place. Similar to the dynamic transition in the ScriptingNarrative-Dance in the Fijian conference title, the "shuttling of implications" traces, constructs, and promises: a performative transition through mimesis, poeisis, and kinesis (Conquergood and Johnson, 2013; Tawa, 2002). It weaves the fabric of a place and permits the water music to be an intrinsically Mwerlap product, produced at the same time as being emblematic of the diasporic entity, Leweton. Just as "... 'life takes place' so does sound and places make sense..." (Feld, 1994) and in the dynamic, rhythmic, spatial anchoring of social groups in diaspora, perhaps kinesis is the new mimesis (Roach, 2010).

\section{The National Conjuncture Phase 2: Leweton to Vila = Dungnao}

The Leweton village in Santo is a commercial success as they have retained enough revenue to purchase a lease over the land on which the village is based and another block across the road. It is indeed the "time of money". The expanded Leweton village, is rebuilt in the image of an idealised village on Merelava, thus closing the loop on the kinesthetic shuttling of implications and (re-)decentring the Mwerlap locative identity. The success has enabled the next stage of articulation at the national level. Leweton have decided to establish another performance village in the Rentapau area just outside Port Vila, the nation's capital. This new village will be called "Dungnao" (the Dungnao Cultural Experience - for the purposes of the tourism industry). ${ }^{5}$ The emergent Dungnao village will be discussed in the following section.

\section{The International Conjuncture: The Leweton Cultural Experience}

The third conjuncture of Mwerlap articulation corresponds to the international scale: touring

5. Both Leweton and Dungnao are registered business names. The community has registered several business names and trade marks, the latter partly in response to some controversies in the tourism industry (see Dick, 2015a). 
overseas and performing at art galleries and international world music festivals, screening the vwww film, participating in academic conferences, environmental symposia, and connecting with other indigenous and diasporic communities. Like the establishment of the Dungnao village in the capital, the articulation of the international site is an ongoing process for the Leweton group. Luganville is already a northern hub of social, cultural, and commercial activity in Vanuatu. Luganville's proximity to the islands of Gaua and Merelava, relative to Port Vila, make it an easier commute by plane, or more commonly, by ship.

Clifford talks about a homology of scale in the rhythm of the commute in pre- and postcolonial lifeways (2001: 469). I suspect that this correlates with commutes of individuals, such as when one of the leaders/managers of the group comes to Australia for an extended stay - often two or three months. But the scale of the Leweton operation - the basic unit is not individual or family, but the entire village - is another factor that tempers the pace of the Mwerlap diasporic expansion. Performances in Santo can happen several times a week and require little planning or preparation beyond what is incorporated into weekly Leweton activities. In terms of both process and scale, these performances are a gentle intensification and touristic inflection of life on Merelava (or Gaua) - a familiar rhythm, a recognizable ethos of place. In contrast, the international tours reflect an ethos of bureaucracy (Handelman, 1998: xxxvii); the processual logic of this ethos attenuates the Mwerlap rhythm with its constant demand for visas, iterations of flights and itineraries, negotiated contracts, renewed passports, medical reports, travel insurance, invoices, receipts, and taxes. All these functions have their corollaries: the missed planes, the rejected visas, the lost passports, the unpaid invoices, the tax liabilities. ${ }^{6}$

Perhaps the attenuated rhythm of the bureaucratic ethos does correlate with precolonial movements of people in the Banks and Torres Islands, the preparations for ceremonies, construction of canoes? For me, being on tour means listening not for the rhythm of visiting and returning, but for a change in the rhythm, a cadence - a specific conflation of rhythm and agency - the subtle shift in intensity that indicates the possibility of an opening for a new "moment of arbitrary closure" - because this is often the harbinger of a re-articulation in the political practice of cultural theory (Slack, 1996: 126): it could be a change in itinerary, a new performance opportunity, a new love interest; but usually it involves a dearticulation and re-articulation and it is usually related to kinship - in Australia, the Melanesian diaspora has a particularly visceral embodiment in the descendants of the South Sea Islanders, the people brought from Pacific Islands to work as slaves and indentured labourers on sugar and cotton plantations. Detailed analysis of this different and more complex form of indigenous Oceanian diasporic articulation is beyond the scope of this article.

The process of establishing Dungnao in the capital also has a bureaucratic ethos. The process started at Leweton in Luganville. After discussions with the community, the leader, Sandy Sur, was required to seek approval from the four nasara. This term nasara has several meanings depending on context. In this case it refers to the process of elders and leaders and broader community coming together in a public forum to make decisions about matters of broad community relevance. ${ }^{8}$ After securing his mandate from the four nasara in Merelava (Lekweal, Lewetmise, Lewetneak, Tesmet) he travelled to Port Vila and approached the Chief (or perhaps "traditional owner" as is more commonly heard in relation to such matters involving land as there is generally no vernacular word for land 'ownership/owner') at Rentapau, around ten kilometers north east of Port Vila. Together, Sandy and the Rentapau Chief presented themselves to the Vaturisu Council of Chiefs (the provincial customary council), and then ultimately to the Malvatumauri National Council of Chiefs (MNCC). At the time of writing Leweton have been given approval to start construction on the Dungnao village at Rentapau, and the Councils have agreed to recognise the rights of the Leweton group to perform the water music in the nasara of the Vaturisu Council of Chiefs. This permission is not embodied in a "traditional/customary" cycad palm leaf (namele) rather it was presented in the form of a letter issued on the letterhead of the MNCC.?

The administrative aspects of the diasporic articulations described above, are also spaces of

6. Coproducing with the Leweton group on the international tours has taught me a lot about these corollaries. In particular I have learnt that the value of strategies of deferment.

7. For a discussion of the role of cultural expression in articulating these connections between ni-Vanuatu and Australian South Sea Islander communities see Dick (2015b).

8. The term can also refer to the place where the forum or meeting and other ceremonies take place: the taking place of place. In both cases it usually refers to the collective self-identifying community who attend the meeting - a 'tribe', perhaps.

9. Compare this with the process that Sandy embarked on in an attempt to resolve the controversy with the tourism industry operators, detailed in Dick (2015a). 
encounter and arenas of confrontation between Mwerlap concerns and the receptions and responses of external structures of power. There are many examples of such encounters, often related to the fact that the aquapelagic nature of the Leweton place-taking performances presupposes a range of unique specifications in terms of staging, technical production, and access to certain plants to harvest materials for costumes and instruments. While Sandy Sur was here in Australia last, he registered the business name "Leweton Cultural Experience" and told me that this was to be the entity that they traded under in Australia and for their international activities. He was also interested in the idea of establishing an Australian site of the Leweton nasara (in this context, the place where the ceremonies and performances can take place but also a safe space where the Leweton group can be at home) - a place to nurture and cultivate the plants that produce the leaves to make costumes, and a place to store the material miseen-scene of performance, costumes, instruments and other bilas (adornment - to borrow a word from Tok Pisin). This had been a problem for the Leweton group in the past. From the first tour, the members of the group recognized immediately that there were specific ways to reorient themselves to the bureaucratic ethos. One way was to ensure that they had no material with them that could be confiscated by Customs and Quarantine Officers on arrival in Australia. So from the very first trip, the Leweton group were interested in what materials were available wherever they were on tour, and what places were available for storing material. Exploring these possibilities generated opportunities for members of the group to spatially orient or emplace themselves by identifying familiar plants, engaging with people willing to open their gardens, and harvesting leaves and flowers. The process of sourcing the materials for performance invariably led to meetings and ceremonies designed to enable the most propitious conditions for the performances.

The storage of material is more problematic, as objects are never just objects; in fact, one wonders if they are ever even objects at all? The ways that the Leweton group relates to the materials suggest that the objects are more like performative entities themselves, embodying a confluence of narratives and identities. They seem to be intersubjectively, constituted coactivities - radically empirical. When members of the group returned to Australia for the second tour, instruments and costumes that had been stored there were inspected and assessed. Some of the items had been removed from storage for convenient retrieval by the group. Other items remained in the places where they were originally stored. This distinction was evidently important to the group. For the items that were still in storage, the inspection applied to a variety of relational trajectories: Who had access to them? How were the items situated with respect to the gender of the people who were near them? Was there any fire and smoke nearby? On the other hand, items that were removed from storage before the group found them were assessed differently; the place and manner of the handover became more significant, though these situations seemed to be assessed less vigilantly on account of the dynamism of the handover. No storage site has emerged as the place of most propensity yet - no place worth taking.

In 2013, the Leweton group was invited to Queensland's Sunshine Coast for a residency at the Floating Land festival - an art festival geared towards environmental awareness with a strong ethos of community engagement. The Leweton group chose to use the entire fee that the festival paid them to pay for extra members of the group to join the tour - the first time that a Leweton tour included both men and women. A part of the village is transported on tour with its relational persons and much (but not all) of its beauty, power, controversies, and internal politics. It becomes a much more complex, exhausting, and exhilarating process. The capacity for revisioning and reformatting performances creates a whole new array of problems as the individual members struggle with the realities of professional touring. The show that is presented to tourists in situ in the Leweton village is a menagerie of different elements: dancing, singing, water music, stringband matto, food preparation, kava, magic shows. The entire show is delivered in under an hour to conform to the expectations of the tourism industry. Thus on the busiest days the group might perform eight shows, at the completion of which everyone is exhausted but it is generalised, full body exhaustion. For the shows that are presented on tour with men and women together such as at the Floating Land festival, each of the individual elements that constitute the in situ show is extended and presented in its own dedicated hour. For the lead singers, the main dancers, and the key musicians, this puts a lot of strain on voices, muscles and techniques - in addition to the exhaustion of touring. The industry demands that individuals deliver their performance in a mechanical, substitutable, standardised way. This is antithetical to the temporal, processual, Mwerlap rhythm of intersubjectively constituted coactivity. But from the perspective of the performing arts industry, there are clear commercial benefits to the development of repertoires for each of the distinct elements. 


\section{Discussion and Deferral}

Throughout this article I bring the context, the background, into focus through the concept of articulation. Yet the Mwerlap diaspora and its configurations as the Leweton group, Dungnao, the Leweton Cultural Experience, etc, is a far more complex and contested entity than I have been able to portray here. As Grossberg explains "the context is not something out there, within which practices occur or which influence the development of practices. Rather, identities, practices, and effects generally, constitute the very context within which they are practices, identities or effects" (Grossberg, 1992: 55; Slack, 1996: 126). The challenge for me is to present the results of my research in a way that reflects the depth, richness, and performativity of the "data" while honouring the conventions of methodological and theoretical frameworks. Working in my radically empiricist way, it is often difficult to balance the requirements of the academy and the expectations of the community; it is difficult to "shape" the "data", as it were, when one is both in and part of the data (Grossberg, 1992: 55-56).

In the Herstory, and the articles that I have published thus far, husbands mediate the voices of their wives and the men present as leaders of Leweton agencies and trajectories. This conceals the fact that my engagement with the group is often directly and exclusively with the women (on tour, for example). In addition to the fact that the women feature in the VWwWM DVD as key protagonists, there are two exceptional cases where I have supported the publishing of perspectives, voices and stories of Mwerlap women unmediated by Leweton men. One is a photographic essay documenting the remarkable work of one of the Mwerlap women, my adopted sister-in-law, Delly Roy (Roy et al., 2015). The other is a case study for a UNESCO report on Gender, Heritage and Creativity in the Pacific (Dick, 2014a).

In the language of Deleuze and Guattari, the place-taking expressions and performances that I have discussed throughout the paper are "territorializing lines" (1987) describing the process of configuration and organisation: the re-constitution of "collective existential territories" (Guattari, 1995). They are also modes of knowing that are dynamic, kinaesthetic, and embodied. Distinct village communities, in constant interaction, with a bias towards diversification and "egalitarian multilingualism, ... a shared history of contact, and ideological emphasis placed on the value of local identities" (François, 2011: 235), are fractal inscriptions of the dynamic interplay of centrifugal and centripetal forces in their social ecology. When a community reaches a certain size it splits itself into smaller communities (fractal inscriptions). Crucially, these forces, dynamics, and inscriptions, as well as contemporary migration patterns, education and work opportunities, colonial and postcolonial structures, and indeed, the new articulated sites of Mwerlap and other indigenous diasporas are all constitutive of the social ecology within which they are forces, dynamics, inscriptions, patterns, opportunities, structures, articulations and diasporas.

I propose that these insights point to contingent openings for social and cultural transformation that can be strategically employed for the advantage of the community in ways that reflect pre-existing indigenous trajectories. The multiscalar Mwerlap conjunctures are an example of these contingent openings that result in the emergence of a new entity from a collaborative encounter between differing formations of humans and non-humans. The cultural innovations, such as those of the Mwerlap community in its codifying of the ëtëtung and the subsequent development of stringband matto take on an emblematic role as chorographic markers of identity. These innovations are an embodiment of the spatial specificity that in northern Vanuatu typically differentiates at the village or local community level (François, 2011, 2012; Hayward, 2015)

But not all of this is relevant to, or even consistent with an understanding of a cultural configuration as an articulated ensemble. Clifford warns that an articulated ensemble is characterised by "its ability to conjoin disparate elements" as "it does not allow you to prefigure it on an organic model, as a living, persistent, "growing" body, continuous and developing through time" (2001: 478). Heeding this warning, the key element that we know to be true from this ensemble of ideas, is that in Melanesia social and cultural differences "tend to be formulated and remembered in terms of specific spatially-bound communities" (François, 2011: 228) and that these communities are chorographically engaged in "a cultural area where each stable social group, recognised with its distinctive - and internally homogeneous identity, can be extremely reduced in size" (ibid.: 232).

The idea of the contested zone - one that reflects the history of Melanesian mobilities and exchanges - is important to this argument because it provides a sense of continuity to the interface between the socio-linguistic innovations that are associated with cultural and linguistic diversity in Vanuatu (and across Melanesia). Languages are social and cultural articulations and performances. And the patterns of exchange within and between languages, reflect other social dynamics. Thus patterns of mobility, such as in the case of the Mwerlap-Leweton conjuncture 
(on the national level) can be understood as a contemporary inflection of an ancient practice. The scale is relevant - to the extent that it specifies intent. The point here is that what may appear to be an effect of divergence on the macro scale is first and foremost the result of events of convergence on the micro scale (ibid.: 231). While we cannot be sure that indigenous Melanesians intended to act con- or di-vergently specifically to affect linguistic diversity, we can be sure that they intended to act convergently, at the scale of local communities with a predisposition to spatial emblematics (François, 2011, 2012). Convergence (insider homogeneity) on this scale results in the diversity on a regional (and linguistically structural) scale. These recent changes are creating new cultural edges, increasing the diversity of ecological, social, and cultural capital upon which people base their livelihoods; but also new opportunities for exploitation, cultural erosion and homogeneity. This raises some interesting questions for the future of the diaspora dialectic. Will the Leweton and Dungnao conjunctures reflect similar dynamic internal convergences within each entity? If so, will those micro-convergences result in macro-divergences between each entity? And for other diasporic communities, is there value in cultivating spatially emblematic markers of identity? Or does this speed up (through microconvergence/macro-divergence) the process of cultural diffusion? Can this be mitigated?

\section{Conclusion}

My intention in this article is to present a perspective on the complex system of knowledge on which the Mwerlap/Leweton people are building strategies for cultural continuity and change. The reader is invited to see this as a performing of place - a negotiated (dis-/em-) placement contextualised by a performativity that embodies the discontinuous parts of both home and diaspora. I have shown that the Mwerlap/Leweton people embody a contingent and temporal grounding of the diaspora/home dialectic. This proposition is not intended to be a critical solution to the antinomy of this dialectic, rather, as discussed in the paragraph above, it is a theoretical and historical re-construction of the Mwerlap/Leweton context. It is also a contextualization of the impasse - the aporia - implied in the "and" in the "Scripting the Development Narrative Through Indicators and Dance". The "and" is about articulating different ways of knowing. Dance is an indicator. Dance indicates. Dance develops. Dance is a narrative and is narrative. As Tawa identifies:
"Indigenous narrative is performative. It conjoins knowledge and its performance. In the experience of its performance- the experience of knowledge as performance knowledge does not precede, succeed, or stand over and above its performance. Knowledge is one with knowing, in a praxis which is its very performance" (Tawa, 2002: 47).

Thus narrative, indicators, and dance are all conjoined in an embodied knowledge. Similarly, the vwowm film, the Herstory, the tours and performances, the photographic essays, and most crucially the infiltration of academic conferences by Melanesian performers, are all embodied modes of knowing that trace the past, present the present, and promise the future.

\section{BIBLIOGRAPHY}

Anderson Ben and Paul Harrison, 2010. The Promise of Non-Representational Theories, in Anderson, B. \& P. Harrison (Eds.), Taking Place: Non-Representational Theories and Geography, Surrey, Ashgate Publishing Ltd,

Arutangai Selwyn, 1987. Vanuatu: Overcoming the Colonial Legacy, in Crocombe, R. (Ed.), Land Tenure in the Pacific (3 ed.), Suva, USP, p. 406.

Bhabha Homi K. ,2012. The Location of Culture Retrieved from http://qut.eblib.com.au/patron/FullRecord.aspx? $\mathrm{p}=653022$

Bolton Lissant, 2003. Unfolding the Moon : Enacting Women's Kastom in Vanuatu, Honolulu, HI, USA, University of Hawaii Press.

Bonnemaison Joël, 1994. The Tree and the Canoe: History and Ethnogeography of Tanna, Honolulu, University of Hawaii Press.

Clifford James, 2001. Indigenous Articulations, The Contemporary Pacific 13 (2), pp. 467-490.

Conquergood Dwight and E Patrick Johnson, 2013. Cultural Struggles: Performance, Ethnography, Praxis, Ann Arbor, University of Michigan Press.

Cullwick Jonas, 2015, September 17. Vanuatu to Host Wansolwora Dance Gathering 2016, Online. Vanuatu Daily post. Retrieved from http://www.dailypost.vu/news/ vanuatu-to-host-wansolwora-dance-gathering/article 5d2e597a-86b4-5f1b-b422-cb0f35481e0b.html

Deleuze Gilles and Felix Guattari, 1987. A Thousand Plateaus: Capitalism and Schizophrenia (2004 ed.), Minneapolis, University of Minnesota Press. 
Dick Thomas, 2014a. Gender, Creativity, and Cultural Heritage: A Case Study of the Vanuatu Women's Water Music. Retrieved from Paris: http://www.unesco.org/new/filead$\mathrm{min} / \mathrm{MULTIMEDIA} / \mathrm{HQ} / \mathrm{CLT} / \mathrm{pdf} / \mathrm{RE}-$ SOURCES Thomas Dickson A Case Study_of the_Vanuatu_Wom.pdf

-, 2014b. Vanuatu Water Music and the Mwerlap Diaspora: Music, Migration, Tradition, and Tourism, AlterNative: An International Journal of Indigenous Peoples 10 (4), pp. 392-407.

-, 2015a. Chorographing the Vanuatu Aquapelago, Shima: The International Journal of Research into Island Cultures 9 (2), pp. 1-22.

—, 2015b. Decolonising Labour Markets: The Australian South Sea Island Diaspora and the Role of Cultural Expression in Connecting Communities, in Szablewska, N. \& S.-D. Bachmann (Eds.), Current Issues in Transitional Justice Vol. 4, Springer International Publishing, pp. 111-131.

Durand Marie. 2013. The Materiality of the Kitchen House: Building, Food and History on Mere Lava, Northern Vanuatu, Doctoral Dissertation, University of East Anglia.

Feld,Steven, 1994. From Ethnomusicology to Echo-Muse-Ecology, Soundscape Newsletter, 8. http://www.acousticecology.org/writings/ echomuseecology.html (accessed 24 September, 2015).

—, 2000. A Sweet Lullaby for World Music, Public Culture 12 (1), pp. 145-171.

- 2012. Sound and Sentiment: Birds, Weeping, Poetics, and Song in Kaluli Expression ( $3^{\text {rd }}$ Thirieth Anniversary ed.), US, Duke University Press.

François Alexandre, 2011. Social Ecology and Language History in the Northern Vanuatu Linkage: A Tale of Divergence and Convergence, Journal of Historical Linguistics 1 (2), pp. 175-246.

- 2012. The Dynamics of Linguistic Diversity: Egalitarian Multilingualism and Power Imbalance among Northern Vanuatu Languages, International Journal of the Sociology of Language, pp. 85-110.

FrançoIs Alexandre and Monika STERn, 2013. Music of Vanuatu: Celebrations and Mysteries, Paris, Label Inédit, Maison de Culture de Monde.

Grossberg Lawrence, 1986. On Postmodernism and Articulation: An Interview with
Stuart Hall, Journal of Communication Inquiry 10 (2): 45-60.

-, 1992. We Gotta Get out of This Place: Popular Conservatism and Postmodern Culture, New York, Routledge.

Guattari Félix, 1995. On the Production of Subjectivity (Bains, P. \& J. Pefanis, Trans.) Chaosmosis: An Ethico-Aesthetic Paradigm, Bloomington, Indiana University Press: $1-32$.

Hall, Stuart. 1980. Race, Articulation, and Societies Structured in Dominance, Paris, UNESCO.

Handelman, Don. 1998. Models and Mirrors: Towards an Anthropology of Public Events, New York, Berghahn Books.

Hau'ofa, Epeli. 1993. A New Oceania: Rediscovering Our Sea of Islands, School of Social and Economic Development, The University of the South Pacific in association with Beake House.

HaYward, Philip, 2012a. Aquapelagos and Aquapelagic Assemblages, Shima: The International Journal of Research into Island Cultures 6 (1), pp. 1-11.

-, 2012b. The Constitution of Assemblages and the Aquapelagality of Haida Gwaii, Shima: The International Journal of Research into Island Cultures 6 (2), pp. 1-14.

-, 2015. Sounding the Aquapelago: The Cultural-Environmental Context of $\mathrm{Ni}-\mathrm{Va}$ nuatu Women's Liquid Percussion Performance, Perfect Beat 15 (2), pp. 113-127.

Hess Sabine, 2009. Person and Place: Ideas, Ideals and Practice of Sociality on Vanua Lava, Vanuatu (Vol. 2), Berghahn Books.

Jolly Margaret, 1994. Women of the Place : Kastom, Colonialism, and Gender in Vanuatu, Chur, Switzerland, Philadelphia, Harwood Academic Publishers.

Leach James, 2014. "the Time of Money": Property and Sovereignty as Alternative Narratives of Land and Value near the Ramu Nico Mining Project (Madang, P.N.G.), Journal de la Société des océanistes 138 (1), pp. 53-62.

Leweton Cultural Group. 2014. Vanuatu Women's Water Music [DVD and booklet]. Luganville, Espiritu Santo: Wantok Musik Foundation and Further Arts.

Lindstrom Lamont, 2011. Vanuatu Migrant Lives in Village and Town1, Ethnology 50 (1), pp. 1-15. 
Madison D. Soyini, 2005. Performance Ethnography, in Madison, D. S. (Ed.), Critical Ethnography: Method, Ethics, and Performance, Thousand Oaks, CA, SAGE Publications, Inc., pp. 149-181.

Maxwell Ian, 2012. Seas as Places, Shima: The International Journal of Research into Island Cultures 6 (1), pp. 27-29.

Mondragon Carlos, 2009. A Weft of Nexus: Changing Notions of Space and Geographical Identity in Vanuatu, Oceania, in Kirby, P. W. (Ed.), Boundless Worlds: An Anthropological Approach to Movement (1 ${ }^{\text {st }} \mathrm{ed}$.), Berghahn Books, pp. 115-134.

Olwig Kenneth R., 2008. Has 'Geography' Always Been Modern?: Choros, (Non)Representation, Performance, and the Landscape, Environment and Planning A 40 (8), pp. 1843-1861.

Patterson Mary, 2002. Moving Histories: An Analysis of the Dynamics of Place in North Ambrym, Vanuatu, The Australian Journal of Anthropology 13 (2), pp. 200-218.

Pratt Mary Louise, 1991. Arts of the Contact Zone, Profession, pp. 33-40.

RoAch Joseph, 2010. Up Front Kinesis: The New Mimesis, Theater 40 (1), pp. 1-3.

Roy Delly, Cristina Panicali, Sarah Doyle and Thomas Dick, 2015. Songs and Stories of Biocultural Diversity: Gender and Creativity in Northern Vanuatu, Langscape 4 (1), pp. 73-77.
SAHLINS Marshall, 1993. Goodby to Tristes Tropes: Ethnography in the Context of Modern World History, The Journal of Modern History 65 (1), pp. 1-25.

SLACK Jennifer Daryl, 1996. The Theory and Method of Articulation in Cultural Studies, Stuart Hall: Critical dialogues in cultural studies, pp. 112-127.

TAwA Michael, 2002. Place, Country, Chorography: Towards a Kinesthetic and Narrative Practice of Place, Architectural Theory Review 7 (2), pp. 45-58.

TAYLOR John Patrick. 2008. The Other Side: Ways of Being and Place in Vanuatu, University of Hawaii Press.

TrYon Darrell, 1996. Dialect Chaining and the Use of Geographical Space, in Bonnemaison, J., C. Kaufmann, K. Huffman, \& D. Tryon (Eds.), Arts of Vanuatu, Bathhurst, Australia, Crawford House Publishing, pp. 170-181.

Turner Nancy J., Iain J. Davidson-Hunt and Michael O'Flaherty, 2003. Living on the Edge: Ecological and Cultural Edges as Sources of Diversity for Social-Ecological Resilience, Human Ecology 31 (3), pp. 439-461.

Wessergo Warren Wevat, Thomas Dick and Sandy Sur, 2014. The History of the Leweton Cultural Village (Dick, T., C. Nalo, \& S. Sur, Trans.). Sydney: Wantok Musik Foundation, Further Arts, MAD Publishing. 
